\title{
Responsabilldoade Ambiental: \\ O Futuro do Princípio da Precaução e da Regulação no Brasil E nos Estados Unidos da América
}

\section{Universidade Federal do Rio Grande do Sul \& Pace University of New York Universidade Federal do Pará \& University of Texas/Austin Coordenadores: Cezar Saldanha Souza Junior e Cláudia de Lima Marques}

\section{IDENTIFICAÇão}

O projeto teve como foco principal o tema da responsabilidade ambiental. Quatro instituições participaram. Pelo Brasil, a Universidade Federal do Rio Grande do Sul-UFRGS e a Universidade Federal do Pará - UFPA. Pelos Estados Ũnidos da América, a PACE University of New York e a University of Texas/Austin. O projeto contou com o apoio de duas organizações não-governamentais: Instituto O Direito por um Planeta Verde, SP, e a WATER KEEPERS ALLLANCE, de New York. Ademais, teve o apoio de um Projeto Interdisciplinar da UFRGS, o Projeto TERMISUL.

Os coordenadores no Brasil foram Cezar Saldanha Souza Junior e Cláudia de Lima Marques. O endereço eletrônico é ppgd@ufrgs.br. A duração do programa foi de quatro anos, ou seja, de 2002, envolvendo todos os passos do planejamento e da preparação, e os anos de 2003, 2004 e 2005, com o intercâmbio de estudantes e de acadêmicos, nas duas direções. Os colegas norte-americanos pediram a prorrogação para continuarem a enviar estudantes. Essa proposta foi aceita com alegria, de modo que continuamos a receber estudantes dos Estados Linidos.

\section{Objettvos propostos}

Foram objetivos propostos para o consórcio: (A) intercâmbio de estudantes; (B) oferecimento de bolsas de pesquisa científica em direito ambiental; (C) otganização e oferecimento de curso de especialização, na UFRGS, em direito ambiental; (D) criação de disciplinas relacionadas ao direito ambiental; (E) desenvolvimento de projetos de pesquisa em direito ambiental. 


\section{Resultados alcanÇADOS}

Todos os objetivos do Consórcio Responsabilidade Ambiental foram alcançados com sucesso. Assim:

(A) no intercâtrabio de estudantes, foram do Brasil, para os Estados Unidos 20 universitátios, 11 da UFRGS e 9 da UFPA; por outro lado, recebemos no Brasil, 5 universitátios do Texas e 4 universitários da PACE.

(B) oferecimento de bolsas de pesquisa científica en direito ambiental: houve forte intercâmbio de professores e de alunos durante o projeto FIPSE-CAPES, sendo que foram organizados quatro eventos. NA UNIVERSIDADE DO TEXAS, dois eventos; na UFRGS, mais três eventos; na PACE UNIVERSITY, um evento; e na UFPA, mais um evento. Foram estabelecidas as Lectures JORDAN YOUNG, na PACE UNIVERSIT'Y, e Lectures TUISKON DICK, ná UFRGS. É de se destacar a publicação dos anais de um Congresso Intemacional intitulado Globalizutgăo Econtiminica, Meio Anbiente e Saciedade Cinil, com o apoio da PACE UNIVERSITY e da UFRGS, e da TINKER FOUNDATION INCORPORATED.

(C) organização e oferecimento de um Curso de Especialização, na UFRGS, de Direito Ambiental Nacional e Internacional, com mais de 104 alunos inscritos e cursantes. Isso possibilitou a publicação dos Cademos do Programa de Pós-Graduação em Direito, "Reflexões Jurídicas sobre o Meio Ambiente, Edição Especial, Vol. 3, n 6, maio de 2005 e os Cadernos do Programa de Pós-Graduação em Direito. Porto Alegre "Cooperação com a University of Texas at Austin e Pace University New York - Harmonização da Legislação Ambiental no Mercosul”, agosto de 2004.

(D) Foram criadas 3 disciplinas relacionadas ao Direito Ambiental, no Departamento de Direito Público e Filosofia do Direito, a saber, Direito Administrativo Ambiental, Direito Constitucional Ambiental e Direito Ambicntal Internacional, alérn de uma nova disciplina na Pós-Graduação de Direito Intetnacional Ambiental, que foi ministrada pela Professora Visitante da PACE UNIVERSITY, a Prof CATHERINE TINKER, com bolsa da CAPES.

(E) Quanto ao desenvolvimento de projetos de pesquisa em direito ambiental., deve-se destacar o sucesso do Grupo de Pesquisa das Professoras Cláudia Lima Marques e Catherine Tinker sobre o Aqüifero Guarani, com organização de eventos na URRGS e na UTEXAS/AUSTIN, juntamente com o Prof. Antonio Herman Benjamin, o que possibilitou a publicaçâo dos cadernos no Pás e a publicação de Artigo Conjunto na Texas International Law Journal, sobre águas no Brasil.

(F) Quanto ao Projeto TERMISUL foi possível publicat nacionalmente o GLOSSÁRIO MULTILÍNGUE DIREITO AMBIENTAL INTERNACIONAL, pela Editora Forense, em 2004, que recebeu o Prêmio da Maison de Dicionnaires, Paris. 
(G) Destaque-se, por fim, que todas as seleções na UFRGS tiveram o acompanhamento de colegas da UT/TEXAS ou/e da PACE UNIVERSITY, o que muito contribuiu para a boa escolha dos intercambistas. Destaque-se que uma das intercambistas brasileiras Tâmara Soares recebeu bolsa da UT/AUSTIN para estágio na Corte InterAmericana de São José da Costa Rica, sendo, depois de formada, a primeira advogada brasileira na Corte. Lá continua a trabalhar.

(H) Maitê Schmidt e Tomás Santos, depois de formados, obtiveram os primeiros lugares na seleção para o Instituto Rio Branco, Escola da Diplomacia Brasileira. Lucas Lixinski recebeu bolsa completa do Instituto de Direitos Humanos da Universidade de Budapeste, Hungria, onde se encontra. Lucas Annes foi aceito na Universidade de Giessen, Alemanha. Miguel Kersling foi aceito cm Harvard para um Mestrado. Ana Borja completou um Mestrado com bolsa Shell em Cambridge e atualmente lá realiza seu doutorado. Mariana Pargendler, aceita em YAL_E, concluiu seu mestrado com sucesso e está cursando PHD. Todos os demais bolsistas concluíram o curso de direito na UFRGS com o mais alto sucesso e encontram-se muito bem colocados no País. Todos eles publicaram artigos sobre o intercâmbio, nos Cadernos do Programa de Pós-Graduação em Direito, em 2004 e 2005 e participaram com relato de suas experiências nos eventos realizados na UFRGS.

\section{Outros Aspectos}

Além dos beneficios e das publicações já relatados, destaque-se, ainda outros aspectos. Os docentes do Projeto, em número de 10 na UFRGS, e os 9 da UFPA, bem assim os dois colaboradores da ONG brasileira participaram ativamente de todos os eventos realizados na UFRGS e na UPPA. Quatro professores da UFRGS realizaram missões no TEXAS, o que muito contribuiu para o doutorado de dois deles, Prof. César Santolin e Igor Danilevicz.

Os doutotandos Roger Raupp Rios e Carlos Augusto Silva realizaram suas pesquisas na tica biblioteca da UT/AUSTTN. As quatro missões da UFPA foram um sucesso. Por sua vez o doutorando Fernando Linhares da UT e o mestrando Jay Bishoff puderam pesquisar na UFRGS e hoje o último deles é funcionário da Conferência de Haia na Holanda.

Três outros doutotandos da UFRGS, Rosangela Bertolo, Tupinambá de Azevedo e Pedro Henrique Figueiredo concluíram seus trabalhos e lograram o título de doutores. $O$ Prof. Cezar Saldanha Souza Junior aproveitou sua presença no TEXAS para ultimar sua pesquisa de livre-docência apresentada na Faculdade de Direito da USP. 


\section{Conclusão}

O trabalho conjunto do Rio Grande do Sul e do Pará foi muito fruúfero. Permitiu estabelecer novos laços científicos e incentivar publicações conjuntas norte-sul do país. Foi também muito importante pata os docentes e discentes a estada em Nova Iorque e no Texas, tendo sido muito bern recebidos sempre.

Destaque-se que a participação das ONGs foi muito positiva, já que organizaram eventos próprios em São Paulo, com publicação dos Anais, e a participação de muitos de nossos docentes e discentes. As referidas entidades ajudaram a promover os eventos na UFRGS, na UFPA, em PACE e na UT/AUSTIN, além de terem participação decisiva no Curso de Especialização da UFRGS e de um outro Curso de Especialização que se realizou tambérn no Pará.

O balanço total do Programa é, portanto, muito positivo, especialmente pois fomenta os estudantes de graduação, e indiretamente fomenta a inserção internacional das Faculdades de Direitos, seus programas de Pós-Graduação e possibilita as pesquisas conjuntas BrasilEstados Unidos em temas de ponta, tanto na graduação como na pós-graduação.

\section{Bibluografia Resultante}

KRJEGER, Maria da Graça, e Outras. Glossário Multilingüe. Direito Ambiental Internacional. Ed. Forense, Rio de Janeiro, 2004, 632 pp.

MARQUES, Cláudia Lima (Org.). Cadernos do Programa de Pós-Graduação em Direito. Porto Alegre "Cooperaçã̃o com a University of Texas at Austin e Pace University New York - Harmonização da Legislação Ambiental no Mercosul”, agosto de 2004, 704 pp.

MARQUES, Cláudia Lima (Org.). Cadernos do Programa de Pós-Graduação em Direito. Porto Alegre, maio de 2005, 352 pp.

The Water Giant Awakes: An Overview on Water Law in Brazil. Antonio Herman Benjamin (Doutorando UFRGS e professor da UT - Austin), Claudia Lima Marques e Catherine Thinker (professota da Pace, NY e professora visitante no PPGDir/UFRGS), in Texas Law Review, (EUA), June 2005, vol. 83, p. 2.185-2.244. 